\title{
Democracia e desenvolvimento sustentável: uma combinação possível
}

\section{Democracy and sustainable development: a possible combination}

\section{Resumo}

Desenvolvimento sustentável e democracia são temas relevantes na sociedade contemporânea e estreitamente relacionados. A efetividade do paradigma do desenvolvimento sustentável pressupõe análise contextualizada sobre os desafios que o Estado Democrático de Direito deve enfrentar para a consecução da qualidade de vida e da dignidade humana. A globalização provocou profundas transformações no cenário político, econômico e social mundial, afetando tanto os regimes democráticos como o próprio conceito de desenvolvimento sustentável. Novos desafios surgiram e objetivam compatibilizar de maneira racional e eficiente democracia e desenvolvimento sustentável. A concretização do desenvolvimento sustentável depende do alargamento da soberania popular, da adoção de espaços democráticos participativos, de novos modelos organizativos e de novas instituições que de fato incorporem os conceitos e preceitos da dignidade humana e da proteção ao meio ambiente.

Palavras-chave: Democracia. Desenvolvimento sustentável. Estado. Globalização. Soberania.

\begin{abstract}
Sustainable development and democracy are important issues in contemporary society and are closely related. The effectiveness of the paradigm of sustainable development presupposes contextualized analysis of the challenges that the democratic state must address to achieve the quality of life and human dignity. Globalization has caused profound changes in the political, economic and social world, affecting both democratic regimes with the concept of sustainable development. New challenges have emerged and aim to reconcile rational and efficient way of democracy and sustainable development. Achieving sustainable development depends on the extension of popular sovereignty, the adoption of participatory democratic spaces, new organizational models and new institutions that actually incorporate the concepts and precepts of human dignity and the protection of the environment.
\end{abstract}

Keywords: Democracy. Sustainable development. State. Globalization. Sovereignty. 


\section{Introdução}

O desenvolvimento sustentável e a democracia constituem pilares fundamentais da sociedade moderna, e compatibilizá-los no desempenho da atividade estatal tem-se tornado nas últimas décadas um dos maiores desafios da humanidade.

As graduais mudanças sociais e políticas, bem como as crises econômicas pelas quais o mundo globalizado passou (e vem passando) nas últimas décadas desde a Ásia à América Latina, passando pelos Estados Unidos e agora na União Europeia - acabaram por criar uma problemática ainda não solucionada: o que devem as democracias priorizar neste momento?

De outro lado, o debate sobre a sustentabilidade alcançou nível global e diante dessas mudanças (sociais, políticas e econômicas), tem incentivado o surgimento de novos arranjos institucionais e de novos fóruns de debate, de novos sistemas de negociação em matéria ambiental e, expressivos investimentos na ciência e pesquisa ambiental, assim como a consolidação de um movimento ambientalista transnacional.

A proteção do meio ambiente na sociedade atual, dentre outras premissas, busca conciliar o desenvolvimento sustentável como uma das formas de viabilizar a concretização do princípio da dignidade humana nas democracias atualmente existentes.

De outro lado, o sistema político (lato sensu), seja em nível internacional, seja no âmbito nacional ou local, vem enfrentando dificuldades que o tornem suficientemente capaz de atender e transformar as crescentes demandas de caráter ambientalista em políticas públicas capazes de promover um modelo alternativo e factível de desenvolvimento. Em se tratando dos fundamentos teórico-conceituais, parte significativa das teorias que abordam e defendem a sustentabilidade do desenvolvimento carecem de maior aprofundamento na dimensão político-democrática. Tal problemática, por certo, constitui um dos mais relevantes fatores limitadores da efetiva implementação de práticas instituidoras do denominado desenvolvimento sustentável.

Tem o presente artigo a finalidade de traçar um esboço sobre a compatibilização do desenvolvimento sustentável e da democracia, observados os pontos antes abordados, de modo a contribuir para o amadurecimento e desenvolvimento de soluções que possam contribuir tiva do princípio da dignidade da pessoa humana na sociedade contemporânea.

\section{A questão ambiental e o desenvolvimento sustentável na atualidade}

A discussão sobre o desenvolvimento sustentável se faz presente em diversos setores da sociedade, tornando-se objeto de estudos, reflexões e debates presentes no âmbito acadêmico, nos movimentos sociais, nas organizações internacionais, nas organizações não governamentais e na mídia.

A proteção do meio ambiente na sociedade atual é ponto de largo debate e suscita ainda inúmeros conflitos, uma vez que na comunidade internacional não há consenso sobre as normas e condutas a serem efetivamente adotadas para equacionar a proteção ambiental e o desenvolvimento humano. As premissas que fundamentam o debate partem basicamente da constatação de que os recursos naturais usados pela humanidade são finitos e o seu emprego racional é necessário para assegurar um desenvolvimento que seja ao mesmo tempo socialmente justo e ambientalmente sustentável.

A Revolução Industrial foi um marco no desenvolvimento e o crescimento do capitalismo, tornando o progresso da indústria a principal fonte de renda e giro de capital, independentemente das consequências daí advindas. Assim, o meio ambiente natural foi perdendo espaço para dar lugar a um meio ambiente produzido pela sociedade moderna, pelo homem, pois as ações humanas originaram diversas transformações que por muitas vezes tiveram implicações perniciosas para o homem e para o meio ambiente. As consequências prejudiciais decorrentes de um mundo essencialmente industrializado trouxeram, com o passar dos anos, a preocupação em proteger o meio ambiente sob pena de esgotamento dos recursos naturais, desencadeando ações governamentais e da própria sociedade com o objetivo de proteger e promover a utilização racional dos recursos naturais disponíveis, em combinação com um modelo de desenvolvimento econômico sustentável, como enfatiza José Carlos Barbieri²:

A preocupação com os problemas ambientais decorrentes dos processos de crescimento e desenvolvimento deu-se lentamente e de modo

BARBIERI, José Carlos. Desenvolvimento e meio ambiente: as estratégias de mudanças da agenda 21. 2. ed. Petrópolis: Vozes, 1997. p. 15. 
muito diferenciado entre os diversos agentes, indivíduos, governos, organizações internacionais, entidades da sociedade civil etc. Pode-se pensar numa evolução que seguiu as seguintes etapas. A primeira etapa baseia-se na percepção de problemas ambientais localizados e atribuídos à ignorância, negligência, dolo ou indiferença das pessoas e dos agentes produtores e consumidores de bens e serviços. As ações para coibir estas práticas são de natureza reativa, corretiva e repressiva, tais como proibições, multas e as atividades típicas de controle da poluição para combater os efeitos gerados pelos processos de produção e consumo. Numa segunda etapa, a degradação ambiental é percebida como um problema generalizado, porém confinado nos limites dos territórios nacionais. Gestão inadequada dos recursos, além das causas citadas acima, são apontadas como causas básicas dos problemas percebidos. Às práticas corretivas e repressivas acrescentam-se novos instrumentos de intervenção governamental voltados para a prevenção da poluição e melhoria dos sistemas produtivos, como são, por exemplo, o estímulo à substituição de processos produtivos poluidores ou consumidores de insumos escassos por outros mais eficientes e limpos, o zoneamento industrial e o estudo prévio de impacto ambiental para o licenciamento de empreendimentos com elevada capacidade de interferência no meio ambiente.

$\mathrm{Na}$ terceira etapa, a degradação ambiental é percebida como um problema planetário que atinge a todos e que decorre do tipo de desenvolvimento praticado pelos países. As ações que se fazem necessárias nessa nova fase começam questionando as políticas e metas de desenvolvimento pelos estados nacionais, geralmente baseadas numa visão economicista; que contestam as relações internacionais, principalmente no que concerne às relações entre os poucos países desenvolvidos e a maioria dos países não desenvolvidos; e incorporam novas dimensões ao entendimento de sustentabilidade, entendimento este que se afasta das propostas baseadas exclusivamente numa visão ecológica. Essa nova maneira de perceber as soluções para os problemas globais, que não se reduzem apenas à degradação do meio ambiente físico e biológico, mas que incorporam dimensões sociais, políticas e culturais, como a pobreza e a exclusão social, é o que vem sendo chamado de desenvolvimento sustentável.

A necessidade crescente de proteger o meio ambiente diante da atividade humana muitas vezes destrutiva e a utilização dos recursos naturais disponíveis de forma racional e compatível com o desenvolvimento econômico são temas que ganharam espaço no cenário dos debates internacionais, inclusive com participação da Organização das Nações Unidas - ONU mediante a realização de conferências e tratados internacionais entre os países participantes (Declaração sobre o Meio Ambiente, aprovada em Estocolmo em 1972; Conferência das Na- ções Unidas sobre Meio Ambiente e Desenvolvimento do Rio de Janeiro, em 1992, entre outras), reforçando assim a relevância da proteção do meio ambiente.

A sociedade contemporânea tem buscado cada vez despertar a conscientização das pessoas e dos entes estatais para a necessidade de desenvolver instrumentos eficientes para a proteção qualidade ambiental, conjugando-se de forma harmônica o desenvolvimento econômico e a tutela do meio ambiente, e assim fazer da política ambiental uma aliada do desenvolvimento sustentável a partir da gestão racional dos recursos naturais na vida em sociedade.

A concretização do denominado 'desenvolvimento sustentável' consubstancia-se na necessária inclusão da proteção do meio ambiente não como um ponto isolado das políticas públicas, mas como parte integrante do processo global de desenvolvimento dos países. Consequentemente deve-se situar a defesa do meio ambiente no mesmo plano, em importância, de outros valores econômicos e sociais igualmente protegidos pela ordem jurídica.

Desenvolvimento sustentável é definido pela Comissão Mundial sobre Meio Ambiente e Desenvolvimento como aquele que atende às necessidades do presente sem comprometer a possibilidade de as gerações futuras satisfazerem as suas próprias necessidades, podendo também ser empregado com o significado de melhorar a qualidade de vida humana dentro dos limites da capacidade de suporte dos ecossistemas.

Não se exige uma estagnação do desenvolvimento econômico das sociedades em prol do meio ambiente, mas sim uma aliança que congregue crescimento econômico, desenvolvimento social e proteção do meio ambiente sadio e ecologicamente equilibrado, possibilitando assim o avanço e o progresso. A grande premissa desse conceito é de que a exploração equilibrada dos recursos naturais, respeitados os limites da satisfação das necessidades e do bem-estar da humanidade nos dias atuais, garantirá a sua preservação no interesse das gerações futuras.

\section{0 impacto do processo de globalização so- bre a democracia}

Deve-se considerar o contexto atual para que se faça um exame coerente acerca da aplicabilidade do desenvolvimento sustentável nos regimes democráticos.

Após a Segunda Guerra Mundial, o mundo passou por sucessivas etapas de profundos avanços no campo 
tecnológico desencadeadas principalmente pela ligação entre conhecimento científico e produção industrial. Esse processo industrial, pautado no conhecimento e na pesquisa, caracteriza a chamada Terceira Revolução Industrial ou Revolução Tecno-científica.

A denominada revolução técnico-científica gerou também um intenso impacto em toda a cadeia de produção de bens e serviços, aumentando a importância do planejamento no processo produtivo em razão da automação calcada em tecnologias de ponta. Esse processo de evolução acabou por reestruturar por completo todo o sistema produtivo e de consumo da sociedade contemporânea, como bem enfatiza Theotônio dos Santos³:

A vida social passou a depender cada vez mais de um planejamento consciente do futuro, que se apóia em exercícios prospectivos de maior ou menor precisão. $\mathrm{O}$ impacto (principalmente em decorrência da automação) sobre a estrutura sócio-econômica foi também decisivo, dando origem a novas relações entre classes e grupos sociais e entre países e regiões. A vida econômica foi totalmente reestruturada. As grandes empresas se converteram na força principal do processo produtivo global. O regime salarial se impôs como relação de produção da maioria da sociedade. A acumulação de capital sofreu drásticas mudanças que afetaram o processo de crescimento econômico, de produção, de reprodução e de novos investimentos.

No plano internacional, as consequências da revolução científico-técnicas foram ainda mais importantes: ela modificou drasticamente as relações econômicas internacionais, ampliadas e diversificadas pela presença das empresas multinacionais que surgiram, nesse período, como uma evolução dramática dos antigos grupos econômicos e trustes que operavam na economia mundial. Como consequência dessas mudanças, desde o final da década de 50 , vem se verificando uma industrialização cada vez mais importante de vários países que compõem a periferia do sistema econômico internacional capitalista. Ao mesmo tempo, no final da década de 60, alguns destes países se converteram de exportadores de matérias-primas em importantes exportadores de produtos manufaturados.

Analisando-se o contexto político-econômico da atualidade, verifica-se que transformações paradigmáticas têm modificado a sociedade global, advindas como
SANTOS, Theotônio dos. A revolução científico-tecnológica, a nova divisão internacional do trabalho e o sistema econômico mundial. Rede de Economia Global e Desenvolvimento Sustentável, Brasil. 28 jun 2002. Disponível em: <http://www.reggen.org.br/midia/documentos/arevocienttecno.pdf $>$. Acesso em: 24 nov. 2012. resultado natural do desenvolvimento e consolidação da economia tecnológica avançada. Estas mudanças trouxeram significativos impactos sobre as relações de trabalho (marcadas pela flexibilização, pela desregulamentação, pela insegurança e informalidade), sobre as possibilidades de efetivação dos objetivos do Estado assistencial (Welfare State), sobre a articulação das relações entre Direito e política nos Estados nacionais.

A globalização constitui verdadeiro processo de transformações de alcance mundial, trazendo consigo uma novel sistemática de desenvolvimento do capitalismo, cujo alcance, compasso e evolução transcenderam as fronteiras nacionais, desprendendo-se dos tradicionais controles políticos e jurídicos, desvinculando-se do modelo econômico estatal, tornando-se o capitalismo sem origens, sem território definido. Analisando o processo de globalização, Giddens ${ }^{4}$ afirma que "a globalização, além de ser econômica, também é política, cultural, tecnológica”.

Os efeitos da globalização não se restringiram às transformações econômicas, apesar de ser este seu maior e mais conhecido efeito, uma vez que a partir da integração das mais diversas atividades econômicas por meio de múltiplos e complexos processos, influenciou sobremaneira o desenvolvimento e consolidação da economia tecnológica avançada.

As modificações operadas pela globalização influenciaram até mesmo o conceito e o próprio exercício da cidadania, um dos pilares do modelo de organização político-jurídica contemporânea nos estados ditos democráticos.

A alteração no modelo de organização do capitalismo, especialmente quando se trata de Estados liberais, tem reflexos diretos sobre as instituições jurídico-políticas, pois há um enfraquecimento do poder soberano do Estado, uma vez que participando da economia globalizada se submete a determinadas restrições que limitam seu poder de atuação na gestão e na intervenção sobre as atividades econômicas dentro de seu território.

Esta cadeia de transformações acaba por enfraquecer a democracia na medida em que há o abrandamento do próprio conceito de Estado liberal como bem salienta Bobbio ${ }^{5}$ :
GIDDENS, Anthony. Un mundo desbocado: los efectos de la globalización en nuestras vidas. Madrid: Taurus, 2001. p. 23. 5 BOBBIO, Norberto. O futuro da democracia. 11. ed. Tradução de Marco Aurélio Nogueira. São Paulo: Paz e Terra, 2000. p. 32-33. 
Disto segue que o Estado liberal é pressuposto não só histórico mas jurídico do Estado democrático. Estado liberal e Estado democrático são interdependentes em dois modos: na direção que vai do liberalismo à democracia, no sentido de que são necessárias certas liberdades para o exercício correto do poder democrático, e na medida oposta que vai da democracia ao liberalismo, no sentido de que é necessário o poder democrático para garantir a existência e persistência das liberdades fundamentais. Em outras palavras: é pouco provável que um Estado não-liberal possa assegurar um correto funcionamento da democracia, e de outra parte é pouco provável que um Estado não-democrático seja capaz de garantir liberdades fundamentais. A prova histórica desta interdependência está no fato de que Estado liberal e Estado democrático, quando caem, caem juntos.

Isto significa dizer que o modelo econômico transnacional acaba por causar a dependência dos Estados em decorrência da força econômica que caracteriza o mercado, e desse modo o Estado não é mais soberano absoluto do controle sobre suas ações de governo e também sobre os seus programas políticos. Consequentemente o seu poder de intervir e gerir a economia nacional (interna) perde força, e de certa forma há uma perda de parcela da soberania.

Se as democracias não estiverem verdadeiramente consolidadas e abertas à evolução, essa 'limitação' da soberania acaba afetando negativamente a força normativa constitucional e diminuindo a efetividade e garantia dos direitos fundamentais. Nesse caso, a própria vivência da democracia fica prejudicada em sua plenitude porque o Estado perde boa parte da competência destinada a implantar instrumentos e espaços para o exercício da democracia. De outro lado, as transformações operadas pela globalização nesse plano mostram-se irreversíveis, de modo que para compensar, ao menos minimamente, essa limitação da soberania estatal, se faz necessário um diálogo harmônico entre os atores globais (Estados nação) direcionado a adoção de providências e atitudes concretas que assegurem, no plano internacional, o efetivo respeito e concretização de direitos fundamentais que tenham ou venham a ser afetados pelo processo de globalização.

No entanto, a sociedade atual ainda não estabeleceu uma coalizão nesse sentido e no interior de diversas nações há a diminuição na utilização de processos decisórios democráticos e de mecanismos participativos, cujo efeito imediato é a debilitação da democracia. Sobre esse desafio é pertinente citar a lição de Bobbio ${ }^{6}$ :

[...] é surpreendente, quase paradoxal, que, enquanto se invoca um reforço do poder público sobre os Estados, assiste-se a um crescente enfraquecimento do poder público no interior de cada um deles, salvo naqueles em que o poder militar ganhou a dianteira sobre o poder político.

O necontratualismo, isto é, a proposta de um novo pacto social, global e não-parcial, de pacificação geral e de fundação de um novo ordenamento social, uma verdadeira "nova aliança", nasce exatamente da constatação da debilidade crônica de que dá provas o poder público nas sociedades econômica e politicamente mais desenvolvidas, ou então - para usar uma palavra corrente - da crescente ingovernabilidade das sociedades complexas. A maior dificuldade que os indivíduos detentores, cada um independentemente do outro, de uma pequena cota do poder soberano, protagonistas do contínuo processo de legitimação e re-legitimação dos órgãos encarregados de tomar decisões coletivas - indivíduos portanto que são, em definitivo, titulares do direito de determinar as cláusulas do novo pacto -, não se contentam mais em pedir, em troca de sua obediência, apenas a proteção das liberdades fundamentais e da propriedade adquirida através das trocas (é a teoria do Estado mínimo de Nozick), mas passaram a pedir que venha inserida no pacto alguma cláusula que assegure uma equânime distribuição de riqueza [...].

Se tal dificuldade será superada ainda não há condições de prever, mas pode-se afirmar que o aumento da complexidade e da diferenciação funcional da sociedade moderna trouxe e vem trazendo novas problemáticas, especialmente no campo dos direitos fundamentais, para o sistema político-administrativo dos Estados em se tratando de sua capacidade de condução e de governabilidade.

\section{0 desenvolvimento sustentável e sua com- patibilização com a democracia}

As alterações geradas pela globalização sobre as estruturas do Estado-nação constituem o contraponto necessário para a análise sobre a possibilidade de compatibilizar os objetivos, as diretrizes e os conteúdos que a expressão desenvolvimento sustentável engloba. Os parâmetros e diretrizes insertas nos textos constitucionais que têm por meta traçar planos, programas que harmonizem

6 BOBBIO, Norberto. O futuro da democracia. 11. ed. Tradução de Marco Aurélio Nogueira. São Paulo: Paz e Terra, 2000. p. 163. 
o desenvolvimento social, o desenvolvimento econômico e a proteção dos recursos naturais acabam por ter baixo grau de efetividade em razão da extenuação do Estado frente às forças do mercado global.

Há que se buscar novas bases e paradigmas destinados a solucionar os problemas da atualidade, as quais necessitam transpor o território nacional e tenham capacidade de abarcar o planeta, de modo a viabilizar a vivência de um democracia real, eficaz na proteção dos direitos fundamentais e sociais e capaz de possibilitar a implantação de um modelo de desenvolvimento econômico que seja sustentável.

A concretização do desenvolvimento sustentável tem relação direta com o desafio político de concepção de espaços democráticos em âmbito global, pois o desenvolvimento sustentável só poderá ser implementado eficazmente em ambientes verdadeiramente democráticos. Entretanto, o paradigma do desenvolvimento sustentável também requer uma nova perspectiva.

Em alguns aspectos a democracia representativa perdeu força, de modo que para uma real e eficiente aplicação do desenvolvimento sustentável seria mais adequado adotar instrumentos típicos de democracia participativa em uma perspectiva local, viabilizando maior participação da sociedade e uma melhor e maior democratização das esferas públicas decisórias sobre políticas e recursos públicos.

Nenhuma proposta envolvendo desenvolvimento sustentável se tornará concreta se não considerar que as soluções para os problemas devem ser produzidas a partir do âmbito da sociedade local, tomando como ponto de partida as transformações que a sociedade global tem sofrido em função das mudanças estruturais do capitalismo. Assim, embora as mudanças no plano político, social e econômico ocorram em escala global, a implementação dessas transformações de forma prática na sociedade clama por ações desenvolvidas localmente.

A soma dessas ações locais, direcionadas a um mesmo objetivo, respeitadas as peculiaridades e vivências de cada sociedade, apresentarão resultados positivos e de alcance mundial, desde que coordenadas por um diálogo global harmônico mantido entre os atores da cena política.

Acserald e Leroy ${ }^{7}$ argumentam que uma socieda-

ACSELRAD, Henri; LEROY, Jean-Pierre. Novas premissas da sustentabilidade democrática. Cadernos de debate Brasil Sustentável e Democrático, Rio de Janeiro, n. 1, p. 11, 1999. de sustentável baseia-se na "construção de uma sustentabilidade democrática no país, reivindicando e fazendo com que as camadas populares tornem-se sujeitos políticos de seu ambiente material, territorial, social, econômico e ambiental".

A sociedade tida como sustentável é aquela na qual o desenvolvimento econômico, social, cultural e em todas as suas demais vertentes está integrado com o meio ambiente natural, respeitando a diversidade biológica e sócio-cultural, o exercício responsável da cidadania, a distribuição eqüitativa das riquezas e das condições dignas de desenvolvimento.

$\mathrm{Na}$ conjuntura das considerações aqui traçadas acerca da democracia, poder local, políticas públicas e descentralização, as palavras de Bianchetti ${ }^{8}$ complementam a discussão:

As propostas de "democracia limitada" ou "democracia protegida" são uma forma de desviar o eixo do conflito que subsiste nas sociedades capitalistas, onde os grupos dominantes buscam conseguir o consenso social para a continuidade de suas ações de apropriação. Esta afirmação se fundamenta no fato de que a proposta neoliberal não propõe a ampliação da participação democrática para fortalecer os controles sobre o aparelho político, e sim opta por uma perspectiva elitista onde os erros da democracia são combatidos com menos democracia e não com maior participação dos historicamente excluídos.

A democracia é um regime político baseado na soberania popular, respeitando a regra da maioria, porém reconhece plenamente os direitos das minorias e o respeito integral aos direitos humanos.

O modelo participativo apresenta-se, então, como um caminho a ser percorrido, no qual se faz latente a possibilidade de incluir os cidadãos no processo decisório e também resgatar a legitimidade das instituições democráticas em uma sociedade global, com contrastes e contradições.

A participação cidadã como instrumento de efetivação da democracia está amparada pela universalização dos direitos sociais, na aplicação do conceito de cidadania e em uma nova compreensão sobre o papel e o caráter do Estado, remetendo à definição das prioridades nas políticas públicas a partir de um debate público, tornando-se mais fácil o envolvimento das comunidades na tomada

8 BIANCHETTI, Roberto G. Modelo neoliberal e políticas educacionais. 2. ed. São Paulo: Cortez, 1999. p. 86. 
de decisões.

O processo de ampliação da participação cidadã, por sua vez, pode ocorrer em dois momentos distintos?:

Ao referir à "participação cidadã”, tenta-se, portanto contemplar dois momentos contraditórios presentes na atual dinâmica política. Primeiro, o "fazer ou tomar parte", no processo político-social, por indivíduos, grupos organizados que expressão interesses, identidades, valores que poderiam se situar no campo do "particular", mas atuando num espaço de heterogeneidade, diversidade, pluralidade. O segundo, o elemento, a cidadania, no sentido "cívico", enfatizando as dimensões de universalidade, generalidade, igualdade de direitos, responsabilidades e deveres. A dimensão cívica articula-se à idéia de deveres e responsabilidades, a propensão ao comportamento solidário, inclusive relativamente àqueles que, pelas condições econômicas, sociais, encontram-se excluídos do exercício dos direitos, do direito a ter direito.

A sustentabilidade (ou desenvolvimento sustentável), dentre outros aspectos, racionaliza o exercício do poder e o Direito, objetivando a concretização da dignidade humana em todas as dimensões, o que implica na existência de marcos democráticos deliberativos, de espaços de conflito e de consenso, como forma de integrar o cidadão no espaço público, aumentando sua capacidade de decisão e autonomia em sociedade.

Pode-se dizer que o desenvolvimento sustentável apresenta-se como uma proposta de alinhamento nos rumos do sistema econômico a partir da adoção de estratégias e instrumentos que permitam a concretização da expressão por meio da harmonização entre o desenvolvimento econômico, o desenvolvimento social e a proteção ambiental.

No Brasil a partir da leitura do artigo 225 da Constituição Federal ${ }^{10}$, verifica-se a existência de afirmação e reconhecimento taxativo pelo constituinte originário do direito de todos ao meio ambiente equilibrado para presentes e futuras gerações, trazendo consigo várias reflexões acerca de seu conteúdo valorativo, especialmente por apresentar a proposta de uma justiça intergeracional (ainda que implicitamente).

O princípio do desenvolvimento sustentável é

TEIXEIRA, Elenaldo Celso. O local e o global: limites e desafios da participação cidadã. 2. ed. São Paulo: Cortez; Recife: EQUIP, 2001. p. 32.

10 BRASIL. Constituição (1988). Constituição da República Federativa do Brasil. Disponível em: <http://www.planalto. gov.br/ccivil_03/Constituicao/Constituiçao.htm>. Acesso em: 28 nov. 2012. norma vetora da política ambiental, da política econômica, da política urbana, encontrando-se positivada no texto constitucional brasileiro em uma perspectiva intergeracional, propondo a aplicação de um novo conteúdo ético para fundamentação da atuação política por meio do desenvolvimento equitativo, prudente e duradouro.

Sua positivação no ordenamento constitucional sinaliza para a importância da adoção de práticas que resultem mudanças estruturais no modelo de desenvolvimento, de forma que este atenda às necessidades sociais e expresse os interesses humanos de forma coordenada com a preservação do meio ambiente. Indubitavelmente, o paradigma do desenvolvimento sustentável vem alargar o sentido da dignidade humana e da proteção aos direitos fundamentais, ao propor o bem-estar e a qualidade de vida para todos, em distintas perspectiva e temporalidade (dimensões presente e futura).

É responsabilidade dos Estados comprometerem-se para efetivar as cartas constitucionais como forma de proteção à democracia, aos direitos humanos. Os Estados precisam tornar efetivas as cartas constitucionais. Precisam criar garantias eficazes para a proteção dos direitos humanos, para promover os direitos sociais como condição ao desenvolvimento econômico e ao progresso.

Acrescente-se também o fato de que a Constituição Federal instituiu o Estado Democrático de Direito, o qual deve buscar a realização da igualdade material por meio da implementação de condições mínimas de vida para todos. E esse objetivo não pode ser concretizado sem a realização da democracia.

Apenas com a adoção de políticas que modifiquem os rumos do desenvolvimento econômico e fortaleçam a democracia participativa se tornará viável a efetivação do direito ao desenvolvimento na sociedade e, por conseguinte, do direito à vivência efetiva da cidadania - a cidadania ambiental.

\section{Considerações finais}

A questão da efetivação dos direitos fundamentais e sociais é tema importantíssimo dentro do exame das funções do Estado, ator principal do controle político sobre a economia. O Estado precisa tecer instituições e mecanismos para o enfrentamento das complexas questões originadas pela globalização, dentre elas, as grandes desigualdades econômicas que se revelam nos espaços sociais, sob a forma de tantas outras de- 
sigualdades.

A proteção aos direitos fundamentais, e, principalmente, aos direitos sociais, é condição sem a qual os Estados, na atualidade, não conseguirão enfrentar a crise da democracia, que está diretamente relacionada às mutações econômicas globais, que cada vez mais geram injustiça social.

Como condição de enfrentamento da crise democrática, é necessário, no caso brasileiro, que se dê máxima efetividade aos direitos sociais como condição para o desenvolvimento humano, como condição para a existência de um regime democrático.

A dialética produção-destruição, questão central no capitalismo contemporâneo e materializada na crise socioambiental, estabelecerá cada vez mais uma lógica entre prudência e os processos de emancipação social, combinando estratégias de reversão dos problemas ambientais em contextos eventualmente dramáticos como desastres e catástrofes ambientais, com a luta pela democratização das sociedades situada no enfrentamento das dissonâncias do poder frente às grandes corporações e suas influências nas instituições, na defesa dos direitos fundamentais e na conquista de processos deliberativos mais próximos dos territórios e das pessoas que nele vivem e trabalham.

Sob este enfoque, a gestão ambiental deverá ser cada vez mais adaptada pela cidadania e consolidada como ferramenta essencial dos cidadãos para governar com soberania o usufruto solidário do seu capital social, natural e cultural. Ainda, o cenário mais favorável a um modelo de desenvolvimento humano mais justo deve incluir uma gestão plenamente democrática, plural e calcada no acesso à informação e ao conhecimento.

À luz do conceito de desenvolvimento sustentável, a existência de um Estado atuante e ao mesmo tempo democrático - Estado Democrático de Direito - constitui um desafio, ao demandar a implementação de políticas públicas inteligentes que objetivem a melhoria da qualidade de vida das camadas populacionais desfavorecidas. Nesse mesmo contexto, devem ser desenvolvidas políticas que incluam os bens ambientais no cálculo econômico do processo produtivo e que consigam cultivar o capital natural para as presentes e futuras gerações.

É de extrema importância a conscientização da comunidade política referente à interdependência entre a questão ambiental e o desenvolvimento econômico-so- como os problemas ambientais locais são interconectados às grandes questões e temas preocupantes do processo de modernização: o modo prevalecente de desenvolvimento capitalista, o modo predatório de apropriação dos recursos naturais, a justiça social, a questão da democratização, a distribuição de poder tanto nos níveis intranacionais como no internacional, a globalização e a liberalização dos mercados internacionais, o endividamento dos países em desenvolvimento, entre outras questões de igual relevância.

Outro fator decisivo para o futuro da democracia está relacionado a como a humanidade e os vários países lidarão com ameaças de grande perigo, sejam catástrofes ambientais ligados a grandes interesses corporativos (caso do setor nuclear e a tragédia de Fukushima), ou mesmo atos terroristas de maior envergadura, os quais possam impactar o fluxo de informações, a mobilidade e o exercício de direitos humanos fundamentais. Também o fim ou a localização em poucos países de recursos naturais estratégicos, sejam eles energéticos (petróleo e urânio) ou vitais (água) nas próximas décadas poderão gerar práticas mais rigorosas de gestão ambiental, mas também disputas que, em situações de tensão, poderão desembocar em conflitos mais generalizados de natureza bélica. Estes processos serão decisivos para a evolução dos níveis de democracia e gestão do ambiente nas próximas décadas, e por isso são importantes elementos orientadores da agenda e da ação política por parte dos grupos que pleiteiam mais sustentabilidade ambiental, democracia e justiça.

\section{Referências}

ACSELRAD, Henri; LEROY, Jean-Pierre. Novas premissas da sustentabilidade democrática. Cadernos de debate Brasil Sustentável e Democrático, Rio de Janeiro, n. 1, p. 11, 1999.

BARBIERI, José Carlos. Desenvolvimento e meio ambiente: as estratégias de mudanças da agenda 21. 2. ed. Petrópolis: Vozes, 1997.

BIANCHETTI, Roberto G. Modelo neoliberal e políticas educacionais. 2. ed. São Paulo: Cortez, 1999.

BOBBIO, Norberto. O futuro da democracia. 11. ed. Tradução de Marco Aurélio Nogueira. São Paulo: Paz e Terra, 2000.

BRASIL. Constituição (1988). Constituição da República Federativa do Brasil. Disponível em: <http://www. 
planalto.gov.br/ccivil_03/Constituicao/Constituiçao. htm>. Acesso em: 28 nov. 2012.

DERANI, Cristiane. Direito ambiental econômico. São Paulo: Max Limonad, 1997.

GIDDENS, Anthony. Un mundo desbocado: los efectos de la globalización en nuestras vidas. Madrid: Taurus, 2001.

SANTOS, Theotônio dos. A revolução científicotecnológica, a nova divisão internacional do trabalho e o sistema econômico mundial. Rede de Economia Global e Desenvolvimento Sustentável, Brasil. 28 jun 2002. Disponível em: <http://www.reggen.org.br/midia/ documentos/arevocienttecno.pdf $>$. Acesso em: 24 nov. 2012.

TEIXEIRA, Elenaldo Celso. O local e o global: limites e desafios da participação cidadã. 2. ed. São Paulo: Cortez; Recife: EQUIP, 2001. 